\title{
BMJ Open Why take the chance? A qualitative grounded theory study of nocturnal haemodialysis recipients who decline kidney transplantation
}

\author{
Meagen M Rosenthal, ${ }^{1}$ Anita E Molzahn, ${ }^{2}$ Christopher T Chan, ${ }^{3}$ \\ Sandra L Cockfield, ${ }^{4}$ S Joseph Kim, ${ }^{3}$ Robert P Pauly ${ }^{4}$
}

To cite: Rosenthal MM, Molzahn AE, Chan CT, et al. Why take the chance? A qualitative grounded theory study of nocturnal haemodialysis recipients who decline kidney transplantation. BMJ Open 2016:6:e011951. doi:10.1136/bmjopen-2016011951

- Prepublication history for this paper is available online. To view these files please visit the journal online (http://dx.doi.org/10.1136/ bmjopen-2016-011951).

Received 17 March 2016 Revised 18 April 2016 Accepted 22 April 2016

CrossMark

For numbered affiliations see end of article.

Correspondence to Dr Robert P Pauly; rpauly@ualberta.ca

\section{ABSTRACT}

Objective: The objective of this study was to examine the factors that influence decision-making to forgo transplantation in favour of remaining on nocturnal haemodialysis (NHD).

Design: A grounded theory approach using in-depth telephone interviewing was used.

Setting: Participants were identified from 2 tertiary care renal programmes in Canada.

Participants: The study participants were otherwise eligible patients with end-stage renal disease who have opted to remain off of the transplant list. A total of 7 eligible participants were interviewed. 5 were male. The mean age was 46 years.

Analysis: A constant comparative method of analysis was used to identify a core category and factors influencing the decision-making process.

Results: In this grounded theory study of people receiving NHD who refused kidney transplantation, the core category of 'why take a chance when things are going well?' was identified, along with 4 factors that influenced the decision including 'negative past experience', 'feeling well on NHD', 'gaining autonomy' and 'responsibility'.

Conclusions: This study provides insight into patients' thought processes surrounding an important treatment decision. Such insights might help the renal team to better understand, and thereby respect, patient choice in a patient-centred care paradigm. Findings may also be useful in the development of education programmes addressing the specific concerns of this population of patients.

\section{INTRODUCTION}

The emergence of nocturnal home haemodialysis (NHD) in the mid-1990s was seen as a welcome addition to end-stage renal disease (ESRD) treatment options. ${ }^{1}$ NHD is typically self-administered 4-6 nights per week, while the patient sleeps, with each treatment lasting 7-9 h. ${ }^{2}$ By increasing the frequency
Strengths and limitations of this study

- The use of grounded theory allowed for the development of a testable theory for understanding patient decision-making.

- Interviews enable an in-depth and detailed examination of patients' experience.

- All participants undertook traditional dialysis modalities prior to starting nocturnal haemodialysis (NHD); therefore, their experiences may not be representative of patients who have only ever done NHD.

and duration of dialysis, this treatment improves markers of mineral metabolism, reduces dependence on antihypertensive medications, liberalises dietary restrictions, and results in better health-related quality of life when compared with conventional haemodialysis. ${ }^{3}$ Evidence suggests that this intensive dialysis provides superior patient survival compared with conventional haemodialysis, perhaps similar to deceased donor transplantation. ${ }^{2}{ }^{4-6}$ Notwithstanding these observations, clinicians appropriately continue to advocate for transplantation for all suitable candidates, ${ }^{7}$ since kidney transplantation is generally regarded as the gold standard treatment for those with ESRD. ${ }^{8-11}$

An environmental scan of two large wellestablished home haemodialysis programmes in Canada reveals that $\sim 15 \%$ of transplantable patients on NHD choose to forgo the gold standard treatment, despite being otherwise medically eligible. This is often against the advice of their care team. It is not currently known why patients choose to remain on NHD when a presumably better treatment is available. Hence, the objective of this study was to examine the factors that influence decision-making to forgo transplantation in favour of remaining on NHD. 


\section{PARTICIPANTS AND METHODS}

Design

A qualitative study design, applying grounded theory, was selected to enable the description and exploration of the basic social process leading to the decision to decline transplantation. ${ }^{12}$ Grounded theory supports theory development through the identification of core categories. ${ }^{13}$

\section{Sample and sampling}

We selected a purposive sample of NHD recipients who declined transplantation. Patients were recruited from two home haemodialysis programmes: the Northern Alberta Renal Program (NARP) and the Toronto General Hospital-University Health Network. Patients were eligible if they were over 18 years of age, English speaking, had received NHD for at least 3 months and declined wait listing for kidney transplantation. Patients were excluded if they were not eligible to be transplanted for any reason (eg, prohibitive comorbid conditions). All participants provided written informed consent to a third party not otherwise involved with this study, or patient care. The research activities being reported are consistent with the Principles of the Declaration of Istanbul.

\section{Data collection}

Semistructured telephone interviews were conducted with each participant because of the wide geographic distribution of the participants. Telephone interviewing has been validated in qualitative research to obtain rich descriptions about sensitive topics. ${ }^{14}$ All interviews were conducted by MMR, who was trained and experienced in conducting such interviews, and who had no prior relationship with study participants. Interviews started with open-ended questions regarding participants' experiences with NHD, and perceptions of transplantation, followed by more detailed and probing questions depending on responses. Interviews lasted $20 \mathrm{~min}$ to $2.5 \mathrm{~h}$ (median time of $30 \mathrm{~min}$ ). All interviews were audio-recorded and transcribed verbatim. Field notes were recorded for each interview.

Baseline clinical information was collected by chart review. This included demographic data, comorbidities, dialysis prescription and measures of routine laboratory variables. These data were used to verify participants' eligibility for kidney transplantation by two independent transplant nephrologists (SLC and SJK).

\section{Analysis}

A constant comparative approach, where every piece of data was compared with other pieces of data was used to identify common themes and a core category. ${ }^{15}$ Research team members (MMR, AEM and RPP) independently examined and coded the interview transcripts, and met on three separate occasions, two of which were during the active data collection phase, to discuss interview findings (MMR is qualitative methods expert, AEM is an experienced qualitative nephrology researcher and RPP is a clinician nephrologist/epidemiologist). This approach resulted in refinement of future interview questions to probe participants about subjects raised by previous participants and added depth to the interviews. Data collection continued until no new findings or themes emerged (ie, saturation).

\section{RESULTS}

A total of seven participants were interviewed; five were male. The mean age was 46 years (range 39-55). Six of the participants were employed; the seventh was a fulltime student. Each had been on NHD for at least 1 year, with some using this therapy for more than 10 years. More detailed participant characteristics are summarised in table 1.

The following sections outline the interview findings beginning with an overview of the core category, "why take a chance when things are going well?', and a description of the medical, psychological and social factors contributing to this category.

\section{Why take a chance when things are going well?}

This category reflected participants' active assessment and weighing of the medical and social risks/benefits of the therapy in question prior to making a decision. Overall, participants reported general satisfaction with their current health and circumstances. Each participant discussed being able to pursue activities important to her or him, including having children and travelling, and did not feel limited by their health condition.

While at the time of the interviews, none of the participants was actively pursuing transplantation; it was also evident that this decision may change if circumstances changed. For example, participant 7 mused about having a transplant in the future and stated, "if it [transplantation] gives me 10,15 years without the machine, I'll be 55-ish...'cause even though having it [dialysis] at home is great, but it's still a machine, you still have to put yourself on." However, as discussed below, she wanted her son to be older before she seriously reconsidered the surgery.

The situation was similar for participant 4 , who mentioned that the sale of his business could free him up for the '2-3-month' recovery time post-transplantation. He also mentioned that he and his wife had discussed the possibility of working with another couple on a paired organ exchange strategy: “...I would get a kidney from another [couple], and my wife would give [her kidney to them]... and that way, you get a perfect match, and you can actually schedule when you want to do the transplant." If these factors could be aligned in the future he seemed open to a transplant.

This core category is supported by four subcategories including negative past experience, feeling well on NHD, gaining autonomy and responsibility (see figure 1). It is noteworthy that these subcategories are not linear stages 
Table 1 Participant characteristics in month of interview*

\begin{tabular}{|c|c|c|c|c|c|c|c|}
\hline & \multicolumn{7}{|c|}{ Participants } \\
\hline & 1 & 2 & 3 & 4 & 5 & 6 & 7 \\
\hline Years with ESRD & 23 & 14 & 5 & 14 & 12 & 11 & 12 \\
\hline Years on NHD & 6 & 1 & 1 & 11 & 11 & 8 & 9 \\
\hline Nights per week of NHD & 4 & 5 & 3 & 5 & 6 & 4 & 5 \\
\hline Hours per night of NHD & 8 & 7.5 & 9 & 8 & 7.5 & 8 & 8 \\
\hline History of cancer & No & Yest & No & Yest & No & No & Yes† \\
\hline History of ischaemic heart disease & No & No & No & No & No & No & No \\
\hline BMI $\left(\mathrm{kg} / \mathrm{m}^{2}\right)$ & 26.2 & 31.5 & 29.7 & 28 & 26.2 & 24.4 & 20.1 \\
\hline Albumin (g/L) & 44 & 36 & 43 & 40 & 33 & 38 & 38 \\
\hline Calcium (mmol/L) & 2.66 & 2.28 & 2.71 & 2.62 & 2.31 & 2.25 & 2.55 \\
\hline Phosphate (mmol/L) & 2.06 & 1.10 & 1.57 & 2.49 & 1.36 & 1.51 & 0.93 \\
\hline Haemoglobin (g/L) & 103 & 98 & 133 & 121 & 119 & 138 & 108 \\
\hline Antihypertensive drug use & No & No & No & Yes & No & Yes & No \\
\hline
\end{tabular}

where the patient's decision is based on a sequential progression through each stage; rather, they are unique (though perhaps overlapping) factors that influenced the decision made by the participants.

\section{Negative past experience}

Participant experience with transplantation was variable: two had had failed transplants, while the remainder had never received a kidney transplant. The adverse effects of immunosuppression played a significant role in participants' perceptions of transplantation (rather than transplantation logistics). For example, as participant 1's transplant was failing, he described his experience with a round of muromonab-CD3 (the murine monoclonal antibody OKT-3) as follows: "My temperature shot up to
104,105 . I was cooking...just in agony on my bed...I was shaking, I was literally bouncing on the bed." Participant 2 described side effects associated with prednisone in the following way: "My feet were just huge; I couldn't even put shoes on...[and] my blood pressure was extremely high; it was over 200 over 170 or something like that."

While participant 3 had not experienced a kidney transplant, he received prednisone to treat his underlying kidney disease. He described his experience as follows:

[I had] breath that smelled like dead meat...I had a big hump, I started getting acne all over my body...I was bloated and sick...I was also too hot, sweating...And I

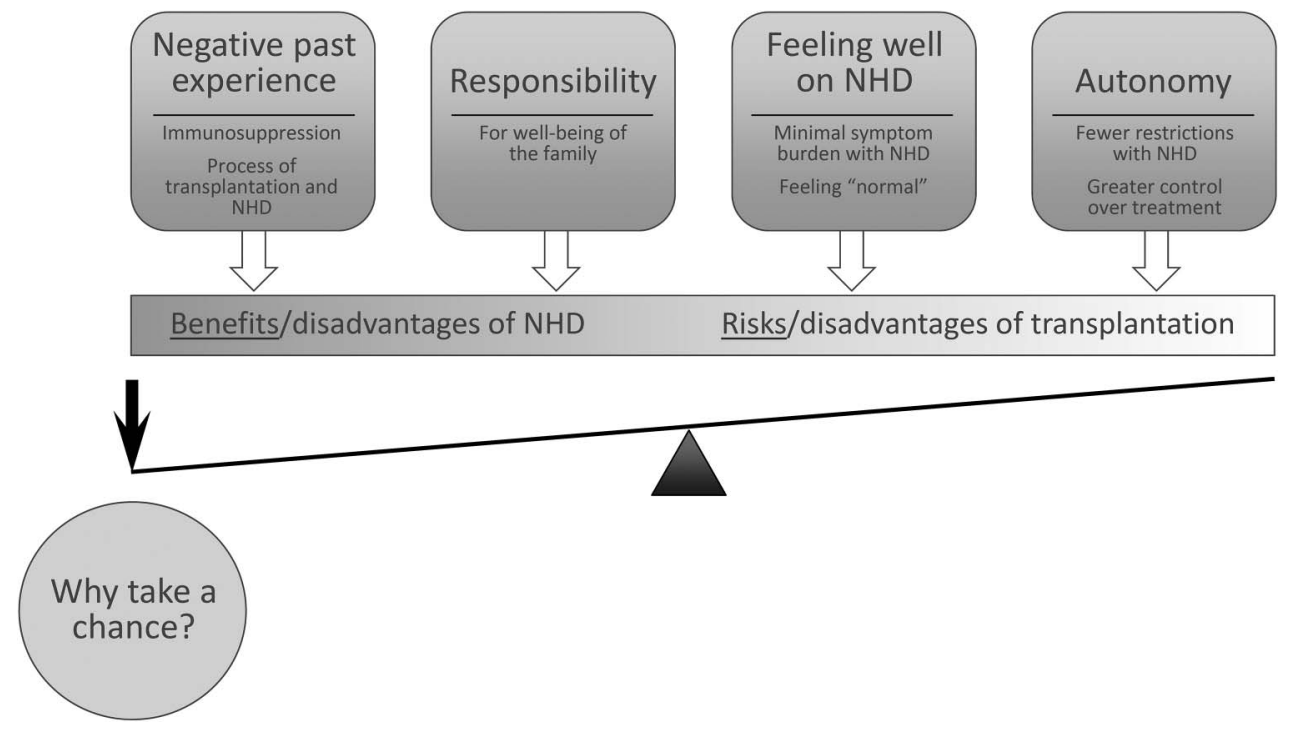

Figure 1 The core category 'why take a chance when things are going well' was identified. The perceptions of risks and benefits of nocturnal haemodialysis (NHD) versus transplantation were informed by four subcategories that appear to be independent though not necessarily mutually exclusive. 
couldn't sleep. When I did sleep, I would have severe nightmares.

Further in relation to participants' concerns with these drugs, participant 7 (a woman of childbearing age contemplating pregnancy), who post-liver transplantation experienced renal failure from "the toxicity of cyclosporine," wanted "...a guarantee that [the drug is] not going to cross the placenta...I didn't want to have a baby that was sick..."

Negative past experience with transplantation was not limited solely to concerns about immunosuppressive drugs. Two participants perceived a mismatch between the medical team's priorities and their own. When describing the loss of his previous transplant, participant 2 stated, "I was actually in [the intensive care unit] because the doctor says, 'No, we have to keep this kidney.' So they tried-it didn't seem like the patient was too much of a concern." Furthermore, one of participant 3's more significant fears, "was to wake up so sick I couldn't even move, and have the doctors patting themselves on the back, looking at all the urine output that my new kidney was producing, and my quality of life was zero".

Also under the umbrella of negative experience, participants discussed the drawbacks of undertaking NHD therapy. For participant 7 , there was a financial burden, because "...you have to pay for water and electricity and things of that nature, and damages to the house if you have floods". With respect to the procedure itself, participant 4 noted, "there's a fair bit of prep time for getting the machine ready...". Participant 5 said, "It's like a job; in the beginning you are slow..." Finally, participants lamented that while travelling, they could not bring their NHD equipment with them. Participant 5 also explained, "And I know, because when I do travel, I switch back to conventional, and I notice a huge [negative] difference [in energy on conventional dialysis] (emphasis added)."

\section{Feeling well on NHD}

All interview participants had experience with conventional dialysis, and discussed NHD in relation to this alternative modality. Participant 5 stated that on NHD "[you have] more energy. [Your] colour will change; like, you'll look normal". She went on to talk about how differences in pump speed affected her: "the [hospital] machine; it's more aggressive $[\ldots]$, so they do put it at 400 pump speed, so I start to crash [after] about two hours...nocturnal is over 8 hours...so it's much easier on your body."

Participants also mentioned that there were fewer food restrictions with the NHD. As participant 4 described, “... I didn't have any restrictions on food or how much I could drink...so I was pretty free." Participant 6 added that in addition to having no food or drink restrictions, "I've gone off almost all of my medications." Participants 3 and 5 also discussed the need for fewer medications (ie, darbepoetin $\alpha$, iron, vitamin $\mathrm{D}$, blood pressure drugs and multivitamins).
Finally, female participants mentioned normalisation of fertility. Both of the female participants had successful pregnancies, without medical complications. As participant 5 described, after being told that her best chance of becoming pregnant was to receive a kidney transplant, "I didn't actually go on the list [for other reasons at the time]. Then I was offered nocturnal dialysis...then something positive happened, and I completely put transplant on the back burner, because I actually conceived..." Participant 7 offered a similar story, saying that, "[the NHD machine] came...and then I went on five times a week, because I was told...it's the best cleaning...I was married... and [then] I got pregnant..."

\section{Gaining autonomy}

Each of the participants also spoke about the value of (re)gaining autonomy. For some, this was about travel. Participant 1 stated, "Well, I can adjust it and do whatever I want. If I need to go on a holiday, [a] 3-day trip or something, I can dialyze before I leave and when I get home...that's the kind of convenience patients need." For participant 2, who was a farmer from a rural community, NHD offered "freedom to do what you have to do during the day. I dialyze at night, and then during the day I can do whatever I need. I don't have to sit [attached to] the machine for $41 / 2$ hours."

Participant 6 liked "the fact that, for lack of a better way to put it, I'm my own boss". For participant 7, NHD enabled "a bit more control over my health; even though I don't have that much, it allows me some control over my life..." Participant 3 described the value of having control over his dialysis schedule in the following way:

The biggest issue for me [is] psychological...the worst thing for me now is having to have a procedure...where they tell me I have to go back to the ward at the hospital...I call it the "zombie ward"...many of them [other patients] are essentially furniture being wheeled in and out to dialyze.

Participant 3 went on to say, "That's the weird thing about home hemo in terms of psychological benefits. I don't know if everyone feels like this, but you can kind of get to this place where...I don't really feel sick." Participant 4 described NHD as, "an alternate to a transplant that you can live a pretty normal life. I travel a fair bit for work, and then we've gone on vacations... and there's never really been any issue with that."

\section{Responsibility}

Finally, participants considered their responsibility to their families when making their treatment decisions. Participant 1's marriage was seriously tested during his kidney transplant. He reported, "My wife's visiting me [in hospital] after work every day, seeing the crap I'm going through...She was alone...she had nobody..." As described earlier, participant 7 considered 
transplantation, but wanted to maintain the status quo: "my son's 8 ; I want him to be a bit older, simply because I want him to be able to take care of himself." Participant 7 was also the primary income earner in her family, so taking time away from work to have a transplant was a low priority. Participant 3, who was a full-time student in a competitive professional programme, said, "if I had to do a cadaveric transplant, I'd probably have to give up [school], because I don't see myself continuing on with it if I have to take another year off...I need to get working for the sake of my family."

\section{DISCUSSION}

In this grounded theory study the core category of "why take a chance when things are going well?' was identified. All participants indicated that their experience with NHD provided them with a good quality of life and the trade-offs of potential adverse events with transplantation, including medical, psychological and social factors, were not worth the risk. This interplay of tradeoffs was informed by four subcategories including 'past negative experience', 'feeling well on NHD', 'gaining autonomy' and 'responsibility', which illustrate both how patients evaluated their current condition, and how they made decisions to accommodate their individual priorities.

While much has been written about patient and caregiver decision-making regarding treatment options in chronic kidney disease generally, ${ }^{17}$ there is a paucity of literature surrounding patient decision-making when choosing to forgo transplantation specifically. The only study to address this question directly reports on crosssectional survey results of 57 Slovenian conventional haemodialysis patients who opted to remain on dialysis. ${ }^{17}$ In this study, the three most common reasons given for forgoing transplantation were fear of immunosuppressive medication side effects $(31 \%)$, the perception that 'transplantation is a lottery' (ie, transplant outcomes were unpredictable; 30\%) and patients' knowledge of peers whose general medical condition had deteriorated following a kidney transplant $(29 \%) .{ }^{18}$

Many of the factors influencing patient decisionmaking around transplantation in this study have been echoed in patient choice of a dialysis treatment option. A recent systematic review of patients with ESRD decision-making choices found that decisions were impacted by the experiences of peers, the timing of the information being provided by healthcare professionals, and a desire by patients to maintain the status quo. ${ }^{17}$ The current study support these observations, though none of our participants identified adverse outcomes of other dialysis patients as influencing their own decisions. This may relate to the lack of generalisability of studies informing the systematic review to the younger, highly functioning and independent NHD patients in our sample, who have limited contact with other patients with ESRD because they dialyse at home.
Furthermore, the objectives of previous studies focused on individual factors' independent contribution to patients' decisions without connecting them to a larger framework relating to the decision-making process, as we have done in the current study. While this is beginning to change with the completion of new qualitative studies, ${ }^{19}$ previous work has largely neglected the social factors including patients' families and employment status, which we found integral to participants' decision-making. Not surprisingly, patients who were working, active and mobile are 'most likely to be involved their own care and decision-making.' ${ }^{20}$ The current study builds on previous literature and proposes a unifying framework for the basic social process underlying patients' decisions to forgo transplantation and remain on NHD.

\section{Limitations}

This study has a number of limitations. The sample size, though adequate for a qualitative study, was small and limited to the Canadian healthcare setting. Participants are not necessarily representative of the broader population of NHD patients. Furthermore, since patient perspectives on NHD and transplantation are presumably influenced by their previous experience with conventional haemodialysis or peritoneal dialysis, the opinions expressed by participants in the current study may differ from the small, but increasing proportion of patients with incident ESRD who have only ever received NHD. Nevertheless, this is the first study in which the factors contributing to decision-making of NHD patients to decline transplantation has been systematically explored.

Currently, there is no evidence to support the optimal treatment choice in patients undergoing NHD who do not wish to be transplanted. Hence, it is important that patients recognise they have a choice regarding treatment, and that health professionals understand how and why patients make decisions regarding modality. This research underscores that a patient-centered approach to decision-making about treatment is critical. This study: (1) provides insight into patients' thought processes surrounding an important treatment decision, (2) allows the renal team to better understand, and thereby respect, patient choice in a patient-centered care paradigm, and (3) may help to identify opportunities for educational interventions of patients' understanding of anticipated risks and benefits of various treatment options. It is important that healthcare providers listen carefully to stories about patients' past experiences, and ask about their future expectations, in order to help them make the best decisions.

\section{Author affiliations}

${ }^{1}$ Department of Pharmacy Administration, University of Mississippi, Oxford, Mississippi, USA

${ }^{2}$ Faculty of Nursing, University of Alberta, Edmonton, Alberta, Canada ${ }^{3}$ Division of Nephrology, University Health Network, University of Toronto, Toronto, Ontario, Canada

${ }^{4}$ Division of Nephrology, University of Alberta, Edmonton, Alberta, Canada 
Acknowledgements The authors would like the acknowledge the important contributions of Maliha Muneer, Research Coordinator, of the Department of Nephrology, University of Alberta, and Margaret McGrath-Chong, RN, of the Home Dialysis Unit of the Toronto General Hospital, who assisted with patient recruitment and consenting. The authors would also like to acknowledge the important contributions of the patients who agreed to participate in this study.

Contributors MMR, AEM and RPP were involved in research idea and study design. MMR contributed to data acquisition. MMR, AEM, SLC, SJK, CTC and RPP were involved in data analysis/interpretation. RPP and CTC provided supervision or mentorship. MMR, AEM, SLC, SJK, CTC and RPP were involved in drafting and final approval of the manuscript. Each author contributed important intellectual content during manuscript drafting or revision and accepts accountability for the overall work by ensuring that questions pertaining to the accuracy or integrity of any portion of the work are appropriately investigated and resolved. MMR takes responsibility that this study has been reported honestly, accurately and transparently; and that any discrepancies from the study as planned (and, if relevant, registered) have been explained.

Funding This work was supported by internal funds at the University of Alberta.

Competing interests None declared.

Ethics approval Health Research Ethics Boards at the University of Alberta and the University of Toronto.

Provenance and peer review Not commissioned; externally peer reviewed.

Data sharing statement No additional data are available.

Open Access This is an Open Access article distributed in accordance with the Creative Commons Attribution Non Commercial (CC BY-NC 4.0) license, which permits others to distribute, remix, adapt, build upon this work noncommercially, and license their derivative works on different terms, provided the original work is properly cited and the use is non-commercial. See: http:// creativecommons.org/licenses/by-nc/4.0/

\section{REFERENCES}

1. Pierratos A, Ouwendyk M, Francoeur R, et al. Nocturnal hemodialysis: three year experience. J Am Soc Nephrol 1998;9:859-68.

2. Pauly RP, Gill JS, Rose CL, et al. Survival among nocturnal home hemodialysis patients compared to kidney transplant. Nephrol Dial Transplant 2009;24:2915-19.

3. Walsh $\mathrm{M}$, Culleton $\mathrm{B}$, Tonelli $\mathrm{M}$, et al. A systematic review of the effect of nocturnal hemodialysis on blood pressure, left ventricular hypertrophy, anemia, mineral metabolism, and health-related quality of life. Kidney Int 2005;67:1500-8.

4. Nesrallah GE, Lindsay RM, Cuerden MS, et al. Intensive hemodialysis associated with improved survival compared with conventional hemodialysis. J Am Soc Nephrol 2012;23:696-705.

5. Tennankore KK, Kim SJ, Baer HJ, et al. Survival and hospitalization for intensive home hemodialysis compared with kidney transplantation. J Am Soc Nephrol 2014;25:2113-20.

6. McFarlane PA. Should patients remain on intensive hemodialysis rather than choosing to receive a kidney transplant. Sem Dialysis 2010;23:516-19.

7. Pauly RP. Survival comparisons between intensive hemodialysis and transplantation in the context of the existing literature surrounding nocturnal and short-daily hemodialysis. Nephrol Dial Transplant 2013;28:44-7.

8. Wolfe RA, Ashby VB, Milford EL, et al. Comparison of mortality in all patients on dialysis, patients on dialysis awaiting transplantation, and recipients of a first cadaveric transplant. $N$ Engl J Med 1999;341:1725-30.

9. Port F, Wolfe R, Mauger E, et al. Comparison of survival probabilities for dialysis patients vs cadaveric transplant recipients. JAMA 1993;270:1339-43.

10. Dew M, Switzer G, Goycoola J, et al. Does transplantation produce quality of life benefits? A quantitative analysis of the literature. Transplantation 1997;64:1261-73.

11. Joseph J, Baines L, Morris M, et al. Quality of life after kidney and pancreas transplantation: a review. Am J Kidney Dis 2003;42:431-45.

12. Strauss A, Corbin J. Basics of qualitative research. Thousand Oaks, CA: Sage, 1998.

13. Patton MQ. Qualitative research and evaluation methods. Thousand Oaks, CA: Sage Patton, 2002.

14. Novick $\mathrm{G}$. Is there a bias against telephone interviews in qualitative research? Res Nurs and Health 2008;31:391-8.

15. Suddaby R. From the editors: what grounded theory is not. Acad Manage J 2006;49:633-42.

16. Morse JM, Coulehan J. Maintaining confidentiality in qualitative publications. Qual Health Res 2015;25:151-2.

17. Morton R, Tong A, Howard K, et al. The views of patients and carers in treatment decision making for chronic kidney disease: a systematic review and thematic synthesis of qualitative studies. BMJ 2010;340:c112

18. Nizic-Kos T, Ponikvar A, Buturovic-Ponikvar J. Reasons for refusing kidney transplantation among chronic dialysis patients. Ther Apher Dial 2013;17:419-24.

19. Walker RC, Howard K, Morton RL, et al. Patient and caregiver values, beliefs and experiences when considering home dialysis as a treatment option: a semi-structured interview study. Nephrol Dial Transplant 2016;31:133-41.

20. Fadem S, Walker D, Abbott G, et al. Satisfaction with renal replacement therapy and education: the American Association of Kidney Patients survey. Clin J Am Soc Nephrol 2011;6:605-12. 